\title{
Redox cycling of a copper complex with benzaldehyde nitrogen mustard-2-pyridine carboxylic acid hydrazone contributes to its enhanced antitumor activity, but no change in the mechanism of action occurs after chelation
}

\author{
YINLI YANG $^{1 *}$, CUIPING LI $^{1 *}$, YUN FU $^{1}$, YOUXUN LIU $^{1}$, YU ZHANG $^{1}$, YANFANG ZHANG $^{1}$, PINGXIN ZHOU $^{1}$, \\ YANBIN YUAN ${ }^{2}$, SUFENG ZHOU ${ }^{3}$, SHAOSHAN $\mathrm{LI}^{2}$ and CHANGZHENG LI ${ }^{1,3}$ \\ ${ }^{1}$ Department of Molecular Biology and Biochemistry, Xinxiang Medical University; ${ }^{2}$ Department of Surgery, The Third \\ Affiliated Hospital of Xinxiang Medical University; ${ }^{3}$ Henan Collaborative Innovation Center of Molecular Diagnostics \\ and Laboratory Medicine, Xinxiang Medical University, Xinxiang, Henan 453003, P.R. China
}

Received October 7, 2015; Accepted November 5, 2015

DOI: $10.3892 /$ or.2015.4530

\begin{abstract}
Many anticancer drugs used in the clinical have potent metal chelating ability. The formed metal complex(es) may exhibit improved (or antagonistic) antitumor activity. However, the underlying mechanism has received limited attention. Therefore, investigation of the mechanism involved in the change upon chelation is required to extend our understanding of the effects of various drugs. In the present study, the proliferation inhibition effect of benzaldehyde nitrogen mustard-2-pyridine carboxylic acid hydrazone (BNMPH) and its copper complex on tumor cell lines was investigated. The copper chelate exhibited almost a 10-fold increase in antitumor activity (with $\mathrm{IC}_{50}<5 \mu \mathrm{M}$ ). The results showed that both BNMPH and its copper complex induced reactive oxygen species (ROS) generation, and caused upregulation of caspase 8 and Bax as well as the downregulation of Bcl-2, indicating that apoptosis was involved in the cytotoxic effects. DNA fragmentation noted in the comet assay further supported ROS involvement. The present study indicated that BNMPH and its copper complex effectively induced $\mathrm{S}$ phase arrest and the cell cycle arrest was associated with the downregulation
\end{abstract}

Correspondence to: Professor Changzheng Li, Department of Molecular Biology and Biochemistry, Xinxiang Medical University, 601 Jinsui Road, Xinxiang, Henan 453003, P.R. China

E-mail: changzhenl@yahoo.com

Dr Shaoshan Li, Department of Surgery, The Third University Hospital, Xinxiang Medical University, 601 Jinsui Road, Xinxiang, Henan 453003, P.R. China

E-mail: shaoshanlioo1@sina.com

*Contributed equally

Key words: benzaldehyde nitrogen mustard-2-pyridine carboxylic acid, proliferation inhibition, reactive oxygen species, apoptosis, autophagy of cyclin D1. The formation of acidic vesicular organelles (AVOs) and an increase in cleaved LC3-II demonstrated that autophagy occurred in the HepG2 cells treated with the agents. Taken together, BNMPH and its copper complex exhibited proliferation inhibition via apoptosis, cell cycle arrest and autophagy, which was dependent on ROS. The enhanced antitumor activity of the copper complex was due to its redoxcycling ability, but the mechanism was not altered compared to BNMPH. Our findings may significantly contribute to the understanding of the anti-proliferative effect of BNMPH and its copper complex.

\section{Introduction}

Cancer is one of the most deadly diseases, and chemotherapy is still the main treatment option (1). Alkylating agents are a class of anticancer drugs which act by inhibiting the transcription of DNA into RNA thereby halting protein synthesis. Nitrogen mustard was the first used DNA alkylating agent, which launched the modern era of cancer chemotherapy, while the discovery of cisplatin cis-diamminedichloroplatinum (II) was one of the most significant events due to its high effectiveness in treating a variety of cancers (2). However the side-effects of these agents (toxicity to the bone marrow and gastrointestinal tract) limit their wide use. Thus, identification of new anticancer drugs to improve therapeutic effectiveness and selectivity is currently a 'hot' topic in medicine science. To minimize the side-effects, different strategies have been proposed, such as conjugation with an encapsulation of drugs into albumin nanoparticles (3), antibody-directed conjugates (4) and DNA-directed conjugates $(5,6)$ in an attempt to improve the selectivity of drugs, but few have achieved successful clinical results.

Many drugs used in the clinic have potent chelating ability, such as doxorubicin, ciprofloxacin, mercaptopurine and chloroquine, and have been shown to form metal complexes in vitro or in vivo (7-9). In vitro studies have demonstrated that the formed metal complexes exhibit enhanced (synergism) 
antitumor activity (10), indicating that their cytotoxicity at least partially is related to their metal chelating ability. Moreover, this circumstance was also found in many other metal complexes, in which the ligands have or do not have biological activity $(8,10,11)$. Normally, we use the ambiguous term, 'synergism' to describe this phenomenon; however, whether or not the metal complexes exhibit enhanced activity via a mechanism similar to the ligands has received less attention. This has hampered our understanding and identification of various drugs. Therefore, investigation of the differences in these mechanisms is crucial.

In a previous study, we conjugated DNA alkylating agent (benzaldehyde nitrogen mustard) with a metal chelator (pyridinecarboxylic acid hydrazide) to utilize cell cycle non-specific nitrogen mustard and ROS generation of the chelator upon capturing iron from a labile-iron pool. Thus, it may enhance their effectiveness by a multi-target mode of action $(12,13)$. As predicted, the conjugates indeed had stronger antitumor activity compared to the chelator or the DNA alkylating agent. Notably, we found that the copper complexes formed by the conjugates had excellent antitumor activities, as found in numerous studies (14-16). Unfortunately, few related studies have revealed the underlying mechanism $(14,17)$. In order to extend our previous study, in the present study the antitumor mechanism of action of benzaldehyde nitrogen mustard 2-pyridine carboxylic acid hydrazone (BNMPH) and its copper complex against different cell lines was investigated. The results indicated that both agents shared a similar mechanism of action via ROS generation, cell cycle arrest, apoptosis and autophagy. Yet, the difference in ROS formation which occurred for the copper complex was involved in Fenton-like redox cycling, which may have contributed to its enhanced antitumor activity compared to BNMPH.

\section{Materials and methods}

Materials. All reactants and solvents were AR grade. MTT, ethidium bromide (EB), RPMI-1640 medium and agarose were purchased from Sigma. LC3 antibody was obtained from Proteintech Group (Wuhan, China); cyclin D1, caspase 8 , $\beta$-actin, Bax and Bcl-2 were purchased from Boster (Wuhan, China).

Preparation of benzaldehyde nitrogen mustard-2-pyridine carboxyl acid hydrazone (BNMPH) and its copper complex. BNMPH and its copper complex were prepared as previously described (13). The synthesized BNMPH was also characterized by NMR. ${ }^{1} \mathrm{HNMR}: 11.85(\mathrm{~s}, \mathrm{H}), 8.72(\mathrm{~d}, \mathrm{H}$, $\mathrm{J}=4 \mathrm{~Hz}), 8.53(\mathrm{~s}, \mathrm{H}), 8.14(\mathrm{~d}, \mathrm{H}, \mathrm{J}=8 \mathrm{~Hz}), 8.08(\mathrm{~m}, \mathrm{H}), 7.67(\mathrm{~m}, \mathrm{H})$, 7.59(d, 2H, J=8 Hz), 6.87(d, 2H, J=8 Hz), 2.53(d, 2H, J=4Hz).

The structure of the BNMPH copper complex based on previous characterization is shown in Fig. 1A.

Proliferation inhibition of BNMPH and its copper complex. Stock solutions of the agents were prepared in dimethylsulfoxide (DMSO). Human colorectal carcinoma cell line (HCT-116) and liver carcinoma cells (HepG2) were cultured in RPMI-1640 medium supplemented with $10 \%$ fetal calf serum (FCS) and antibiotics. The cells in the exponential growth phase $\left(2 \times 10^{5} / \mathrm{ml}\right)$ were seeded equivalently into a 96 -well plate and various concentrations of the BNMPH-Cu complex (or BNMPH) were added after the cells were adherent. Following a 48 -h incubation at $37^{\circ} \mathrm{C}$ in a humidified atmosphere of $5 \%$ $\mathrm{CO}_{2}, 10 \mu \mathrm{l}$ MTT solution $(5 \mathrm{mg} / \mathrm{ml})$ was added to each well, followed by further incubation for $4 \mathrm{~h}$. The cell culture was removed by aspiration, and DMSO (100 $\mu \mathrm{l} /$ well) was added to dissolve the formazan crystals. The measurement of absorbance of the solution in relation to the number of live cells was performed on a microplate reader (MK3; Thermo Scientific) at $570 \mathrm{~nm}$. Percent growth inhibition was defined as the percentage of absorbance decrease within the appropriate absorbance in each cell line. The same assay was performed in triplicate.

ROS detection. $\mathrm{H}_{2} \mathrm{DCF}-\mathrm{AM}$ is converted to dichlorofluorescein (DCF) according to a study by Jakubowski and Bartosz (18). Briefly, $0.25 \mathrm{ml}$ of $2 \mathrm{mM} \mathrm{H}_{2} \mathrm{DCF}-\mathrm{AM}$ in absolute ethanol was added to $2.0 \mathrm{ml}$ of $10 \mathrm{mM} \mathrm{NaOH}$ and allowed to stand at room temperature for $30 \mathrm{~min}$. The hydrolysate was then neutralized with $10 \mathrm{ml}$ of $25 \mathrm{mM}$ sodium phosphate buffer (pH 7.2) and kept on ice for use. Reaction mixtures contained $0.4 \mu \mathrm{M}$ DCF in $50 \mathrm{mM}$ sodium phosphate buffer $(\mathrm{pH} 7.4)$ and eventual addition of $25 \mu \mathrm{l}$ of $1 \mathrm{mM} \mathrm{NH}_{4} \mathrm{FeSO}_{4}$ or $1 \mathrm{mM}$ $\mathrm{BNMPH}$ in a total volume of $4.0 \mathrm{ml}$. After addition of $0.2 \mathrm{ml}$ of $4 \mathrm{mM} \mathrm{H}_{2} \mathrm{O}_{2}$, fluorescence was measured using an FC-960 spectrofluorimeter (excitation at 488 and emission at $525 \mathrm{~nm}$ ). The measurements were conducted at room temperature.

Measurement of intracellular ROS production. The intracellular ROS production was measured according to the manufacturer's recommendations (Beyotime Biotechnology, Beijing, China). Approximately $1 \times 10^{6}$ HepG2 cells were collected and washed with phosphate-buffered saline (PBS). The cell pellet was resuspended in DCFH-DA containing serum-free culture medium and incubated for $30 \mathrm{~min}$. The stained cells were re-collected and washed with serum-free culture medium. Then, $100 \mu \mathrm{l}$ of the cells was transfered to PCR tubes and the test compound was added. Following a 1-h incubation, the cell suspension was used directly for ROS determination on an FC-960 spectrofluorimeter by excitation at $488 \mathrm{~nm}$ and emission at $525 \mathrm{~nm}$.

Comet assay. The comet assay was adapted as previously described (19). HepG2 cells were treated with or without the investigated agents (40 and $80 \mu \mathrm{M}$ for BNMPH, or 2.5 and $5 \mu \mathrm{M}$ for the BNMPH-Cu complex) with a 24-h incubation in a humidified atmosphere of $5 \% \mathrm{CO}_{2}$. The cells were harvested by centrifugation after trypsinization and then embedded in $0.5 \%$ low-melting-point agarose at a final concentration of $1 \times 10^{4}$ cells $/ \mathrm{ml}$. A $20 \mu \mathrm{l}$ aliquot of this cellular suspension was then spread onto duplicate frosted slides that had previously been covered with $1 \%$ normal melting point agarose as a basal layer. Slides were allowed to solidify for $10 \mathrm{~min}$ at $4^{\circ} \mathrm{C}$ before being placed in lysis buffer for $1 \mathrm{~h}[2.5 \mathrm{M} \mathrm{NaCl}$, $0.1 \mathrm{M}$ ethylene diamine tetraacetic acid (EDTA), 0.01 M Tris, $1 \%$ Triton X-100, 10\% DMSO, pH 10.0]. After lysis, the slides were transferred into alkaline buffer for $40 \mathrm{~min}(0.001 \mathrm{M}$ EDTA, $0.3 \mathrm{M} \mathrm{NaOH}, \mathrm{pH}>13.0$ ) to allow the DNA to unwind before migration at $0.66 \mathrm{~V} / \mathrm{cm}$ and $300 \mathrm{~mA}$ for $30 \mathrm{~min}$. All these steps were performed in the dark. After neutralization 
in $0.4 \mathrm{M}$ Tris- $\mathrm{HCl} \mathrm{pH} \mathrm{7.4,} \mathrm{the} \mathrm{slides} \mathrm{were} \mathrm{stained} \mathrm{with} \mathrm{EB}$ $(20 \mu \mathrm{g} / \mathrm{ml})$ and covered with a coverslip. The images were captured using fluorescence microscopy.

Gene regulation of BNMPH and its copper complex. Total RNA was extracted from the cells treated with the investigated agents for $24 \mathrm{~h}$ using TRIzol reagent (Sangon, Shanghai, China) according to the manufacturer's protocol. Two micrograms of total RNA was used for reverse transcription in a total volume of $20 \mu \mathrm{l}$ with the M-MLV reverse transcriptase system (LifeFeng Biological Technology Corp., Shanghai, China). Two microliters of cDNA was subsequently amplified in a total volume of $20 \mu \mathrm{l}$ using the 2X Taq PCR kit (LifeFeng Biological Technology Corp.) according to the conditions recommended by the manufacturer. The sense and antisense primers (synthesized by Shanghai Generay Bioengineering Co. Ltd., Shanghai, China) for $\beta$-actin were 5'-ACACTGTG CCCATCTACGAGG-3' and 5'-CGGACTCGTCATACT CCTGCT-3' (615 bp) that were used as an internal control. The sense and antisense primers for caspase 8 were $5^{\prime}$-AAG TTCCTGAGCCTGGACTACAT-3' and 5'-ATTTGAGCCC TGCCTGGTGTCT-3' (227 bp). The sense and antisense primers for bcl-2 were 5'-TTACCAAGCAGCCGAAGA-3' and 5'-TCССТCCTTTACATTCACAA-3' (309 bp). The sense and antisense primers for bax were 5'-TTTTGCTTCAGGGT TTCATC-3' and 5'-GGCCTTGAGCACCAGTTT-3' (299 bp). The sense and antisense primers for cyclin D1 were 5'-CTG GATGCTGGAGGTCTGCGAGGA-3' and 5'-TGAACTTCA CATCTGTGGCACAGA-3' (400 bp), respectively. RT-PCR was performed on a Nexus Gradient Mastercycler (Eppendorf). The cycling conditions consisted of $94^{\circ} \mathrm{C}$ for $5 \mathrm{~min}$, followed by 30 cycles of $94^{\circ} \mathrm{C}$ for $30 \mathrm{sec}, 53-56^{\circ} \mathrm{C}$ for $30 \mathrm{sec}$ and $72^{\circ} \mathrm{C}$ for $1 \mathrm{~min}$, and a final extension of $72^{\circ} \mathrm{C}$ for $10 \mathrm{~min}$. PCR products were separated on a $1.5 \%$ agarose gel and viewed by DNA green staining. The data were acquired using Tocan 360 gel imager (version 3.2.1 software).

Western blotting was employed to assess the related gene expression at the protein level. Briefly, $1 \times 10^{7}$ HepG2 cells treated with or without the agents were scraped off in lysis buffer (50 mM Tris-HCl, pH 8.0, $150 \mathrm{mM} \mathrm{NaCl}, 1.0 \%$ NP-40, $10 \%$ glycerol and protease inhibitors) and subjected to sonication, following spin down by centrifugation at $14,000 \times \mathrm{g}$. The clear supernatant was stored at $-80^{\circ} \mathrm{C}$. The protein concentration was determined using a colorimetric Bio-Rad DC protein assay on a microplate reader MK3 at $570 \mathrm{~nm}$. Proteins $(30 \mu \mathrm{g})$ were separated on a $13 \%$ sodium dodecyl sulfate-polyacrylamide gel at $200 \mathrm{~V}$ for $1 \mathrm{~h}$. Then, the separated proteins were subsequently transferred onto a PVDF membrane at $60 \mathrm{~V}$ for $1 \mathrm{~h}$. The membrane was washed three times with tris-buffered saline (TBS) and was then blocked for $2 \mathrm{~h}$ in TBS containing $0.1 \%$ Tween-20 and 5\% non-fat skimmed milk. The membrane was incubated at $4^{\circ} \mathrm{C}$ overnight with the primary monoantibody used at a dilution of 1:300 in TBS plus $0.1 \%$ Tween-20 (TBST). The membrane was washed several times with TBST and was subsequently incubated with HRP-conjugated secondary antibody (1:2,000 in TBST) for $1 \mathrm{~h}$ at room temperature. After another wash of the membrane with TBST, the protein bands were detected using a super sensitive ECL solution (Boster Biological Technology Co. Ltd.), and visualized on a Tocan 360 gel imager.
Cell cycle analysis. HepG2 cells $\left(1 \times 10^{5}\right)$ were seeded in a 6-well plate and incubated for $24 \mathrm{~h}$ at $37^{\circ} \mathrm{C}\left(5 \% \mathrm{CO}_{2}\right)$. The medium was replaced with fresh medium supplemented or not (control) with the agents ( 40 and $80 \mu \mathrm{M}$ for BNMPH, or 2.5 and $5 \mu \mathrm{M}$ for the BNMPH-Cu complex). After $24 \mathrm{~h}$ of incubation, the cells were harvested with trypsin, followed by washing with PBS, fixed in $70 \%$ ethanol and stored at $-20^{\circ} \mathrm{C}$. The cellular nuclear DNA was stained using propidium iodide (PI). Briefly, after removing the $70 \%$ ethanol, the cells were washed with PBS and then suspended in $0.5 \mathrm{ml}$ PBS containing $50 \mu \mathrm{g} / \mathrm{ml} \mathrm{PI}$ and $100 \mu \mathrm{g} / \mathrm{ml}$ RNase. The cell suspension was incubated at $37^{\circ} \mathrm{C}$ for $30 \mathrm{~min}$. DNA flow cytometry was performed in duplicate with a FACSCalibur flow cytometer (Becton-Dickinson, USA). For each sample, 10,000 events were collected, and fluorescent signal intensity was recorded and analyzed by CellQuest and ModiFit (Becton-Dickinson).

BNMPH and its copper complex induce autophagy. Cells were seeded into a 24-well flask and treated as described above for the cell viability assay. The cells were treated with different concentrations of the agents (20 and $40 \mu \mathrm{M}$ for BNMPH, or 2.5 and $5 \mu \mathrm{M}$ for the copper complex) for $24 \mathrm{~h}$. For detection of the acidic cellular compartment, acridine orange (or LysoTracker Red; Invitrogen) was used, which emits bright red fluorescence in acidic vesicles but green fluorescence in the cytoplasm and nucleus. After treatment of the cells with the agent, acridine orange was then added at a final concentration of $1 \mu \mathrm{g} / \mathrm{ml}$ (the concentration of LysoTracker Red, as recommended) for a period of $15 \mathrm{~min}$. Following PBS washing, the fluorescent micrographs were captured using an inverted fluorescence microscope.

\section{Results}

Cytotoxicity of BNMPH and its copper complex. Previous studies have demonstrated that BNMPH exhibits a proliferation inhibitory effect against several tumor cell lines $(12,13)$, and its copper complex exhibits much stronger inhibitory activity (12). To probe the underlying mechanism, more tumor cell lines were used to investigate the proliferation inhibition of BNMPH and its copper complex. The dose-response curves of BNMPH-Cu and BNMPH against HepG2 and HCT-116 cell lines are depicted in Fig. 1B and C. As shown in Fig. 1B and C, BNMPH exhibited moderate growth inhibition in the HepG2 $\left(\mathrm{IC}_{50}, 31.6 \pm 1.7 \mu \mathrm{M}\right)$ and HCT-116 cell lines $\left(\mathrm{IC}_{50}, 44.1 \pm 1.5 \mu \mathrm{M}\right)$; however, the BNMPH-Cu complex exhibited a $\sim 10$-fold increase in proliferation inhibition $\left(\mathrm{IC}_{50}\right.$ at $3.5 \pm 0.8 \mu \mathrm{M}$ for HepG2, and $4.5 \pm 0.5 \mu \mathrm{M}$ for HCT-116, respectively). The significant increase was not fully understood based on a synergistic effect between the ligand and copper for the copper ion was not toxic at the investigated concentration, thus it was important to probe the potent mechanism.

$B N M P H$ and its copper complex induce ROS generation. The aim of the introduction of a chelator into an alkylating agent is to enhance ROS production. Thus, it was necessary to determine whether the BNMPH-metal (iron and copper) complex was redox active in Fenton-like reaction since the cytotoxicity of many drugs is correlated with ROS production. As shown in Fig. 2A, BNMPH-Fe significantly promoted ROS 
A<smiles>ClCCN(CCCl)c1ccc(-c2nn3cc2[Si](Cl)(Cl)C2=CC=CC2=C3)cc1</smiles>

B

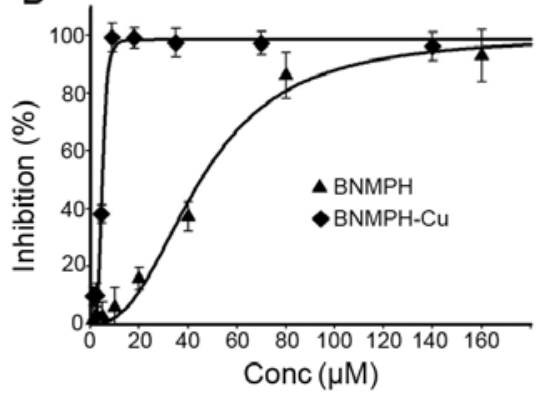

C

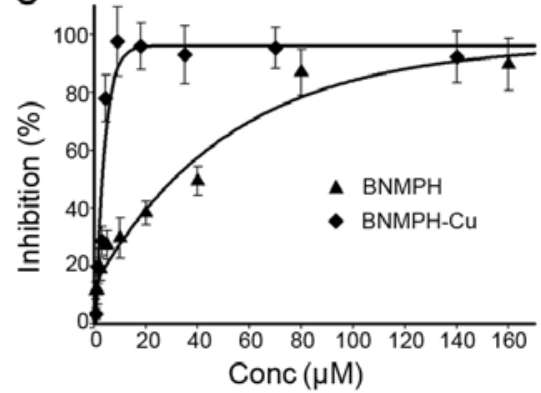

Figure 1. The structure of BNMPH and its copper complex (BNMPH-Cu) and their proliferation inhibition effects. (A) Chemical structure of BNMPH-Cu. Cytotoxicity of BNMPH and BNMPH-Cu against the (B) HepG2 cell line $\left(\mathrm{IC}_{50}, 31.6 \pm 1.7 \mu \mathrm{M}\right.$ for $\mathrm{BNMPH}$ and $3.5 \pm 0.8 \mu \mathrm{M}$ for $\left.\mathrm{BNMPH}-\mathrm{Cu}\right)$; and the $(\mathrm{C}) \mathrm{HCT}-$ 116 cell line $\left(\mathrm{IC}_{50}, 44.1 \pm 1.5 \mu \mathrm{M}\right.$ for $\mathrm{BNMPH}$ and $4.5 \pm 0.5 \mu \mathrm{M}$ for $\left.\mathrm{BNMPH}-\mathrm{Cu}\right)$.

A

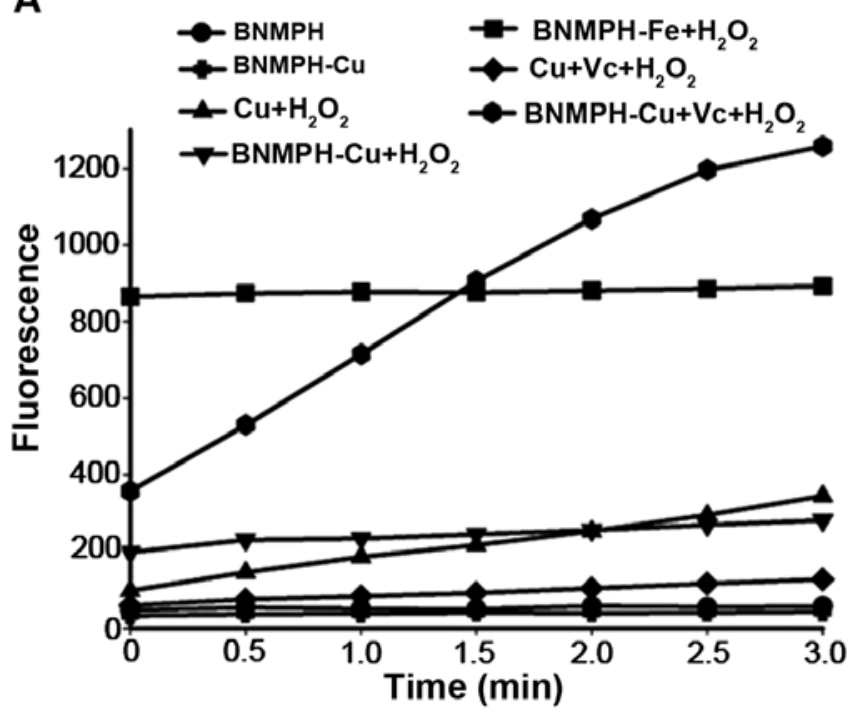

B

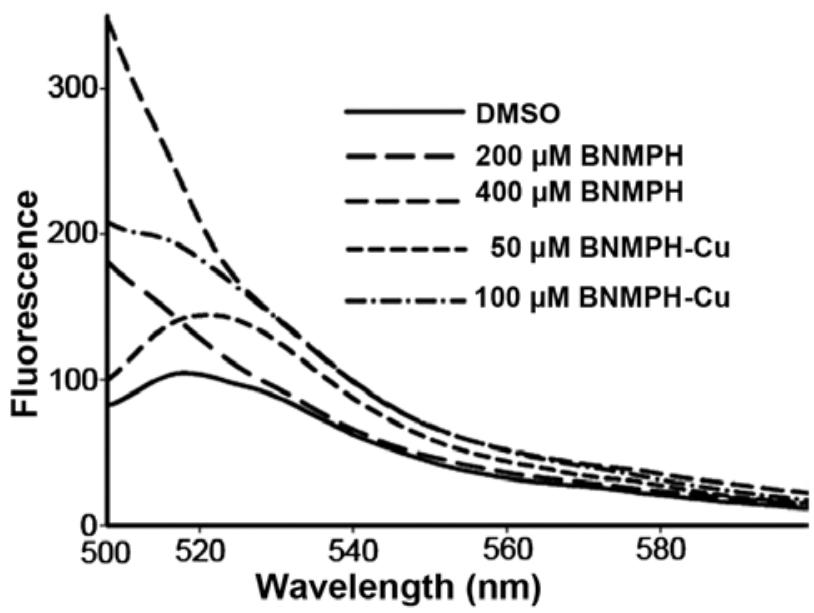

Figure 2. BNMPH and its copper complex (BNMPH-Cu) induce ROS in vitro and in vivo. (A) In vitro ROS generation by BNMPH's iron or copper complex involved Fenton-like reaction, the ROS content was measured by DCF fluorescence. The ability of ROS generation was enhanced by the addition of Vc in BNMPH-Cu involved reaction compared to copper iron; (B) in vivo, the ROS production after exposure of the BNMPH and its copper complex. The DMSO control was also included.

generation based on the DCF fluorescence intensity. Similarly the BNMPH-Cu complex exhibited the same behavior in the Fenton-like reaction except it had weaker ability. However, the ROS level was significantly increased when the BNMPH-Cu was reduced by ascorbic acid $(\mathrm{Vc})$ compared to that of the copper ion, implying that BNMPH-Cu in a reduced environment was more efficient at ROS generation. To further determine the correlation between ROS and cytotoxicity in vivo, the HepG2 cells were treated with the agents and stained using DCFH-DA. As shown in Fig. 2B, both BNMPH and its copper complex induced ROS formation, indicating that ROS were involved in the proliferation inhibitory activity of the agents. It was noted that BNMPH-Cu had a much stronger ability to induce ROS, while the ability of BNMPH was weaker in vivo. The difference in ROS generation in vivo may suggest that both agents used a different mode to generate ROS. The copper complex may utilize redox cycling, while BNMPH may depend on the availability of a labile iron pool or another pathway.
BNMPH and its copper complex induce cell apoptosis. ROS play a crucial role in cell growth and apoptosis. ROS generation induced by BNMPH and its copper complex prompted us to investigate the underlying molecular mechanism. Thus, RT-PCR was conducted to determine the changes in apoptotic genes in the HepG2 cells following treatment with BNMPH or its copper complex. As shown in Fig. 3A, the expression levels of caspase 8 and Bax were increased, while Bcl-2 was not evident at the mRNA level. To further confirm that the cytotoxic effects of the agents involved apoptosis, western blotting was used to determine the changes in levels of the corresponding proteins. As expected, an increase in caspase 8 and Bax, and a decrease in Bcl-2 were observed in the cells following exposure to the agents (Fig. 3B), indicating that they exhibited cytotoxicity via apoptosis and shared a similar pathway.

Cellular DNA fragmentation by BNMPH and its copper complex. It is well documented that ROS cause genetic DNA breakage of host cells and contribute to cytotoxicity. To further 

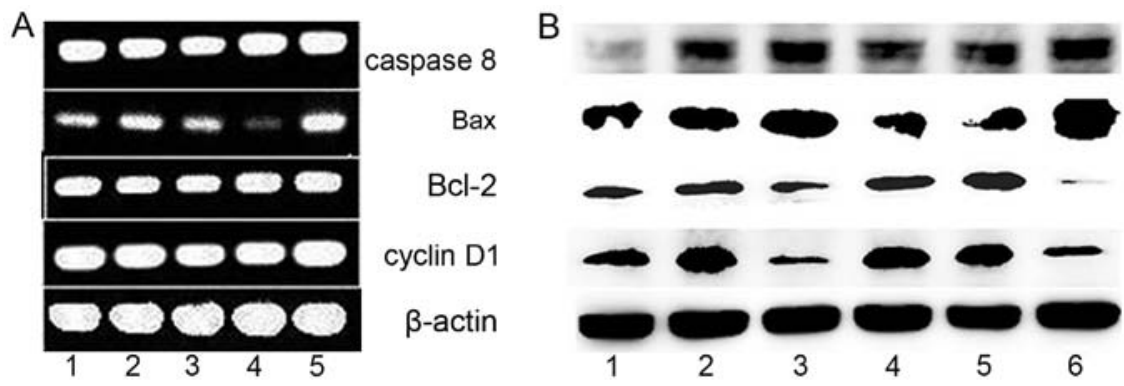

Figure 3. The effect of BNMPH on the regulation of apoptosis-related genes in HepG1 cells in the absence or presence of the agents after incubation for $24 \mathrm{~h}$. (A) Gene regulation at the mRNA level: lane 1, $40 \mu \mathrm{M}$ BNMPH; lane 2, $20 \mu \mathrm{M}$ BNMPH; lane 3, 0.75\% DMSO; lane 4, $3 \mu \mathrm{M} \mathrm{BNMPH-Cu}$; lane 5, 4.5 $\mu \mathrm{M}$ BNMPH-Cu. (B) Gene regulation at the protein level: lane 1, 0.5\% DMSO; lane 2, $12.5 \mu \mathrm{M} \mathrm{BNMPH;} \mathrm{lane} \mathrm{3,} 25 \mu \mathrm{M}$ BNMPH; lane 4, 0.75\% DMSO; lane 5, $1.5 \mu \mathrm{M}$ BNMPH-Cu; lane 6, $3 \mu \mathrm{M}$ BNMPH-Cu.
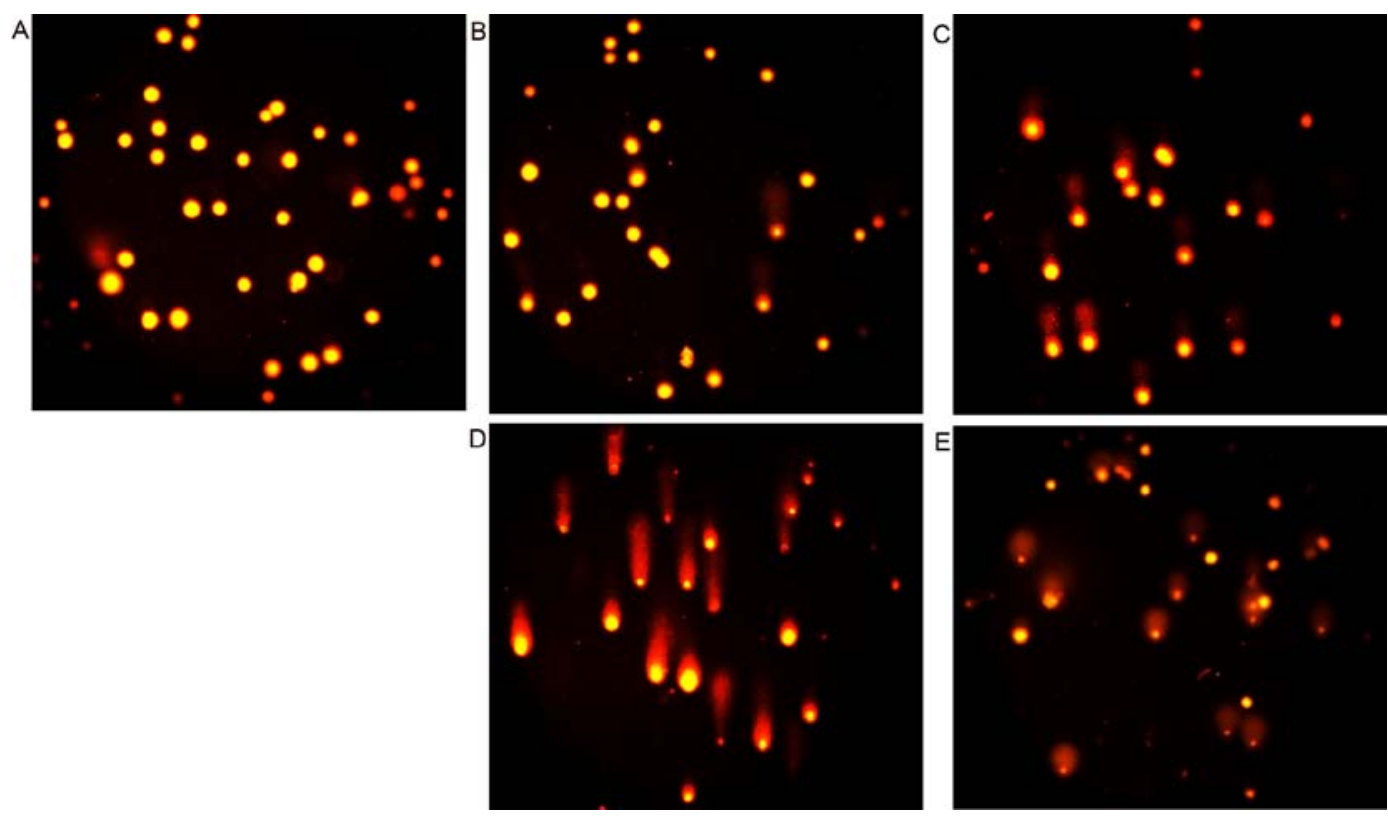

Figure 4. In vivo DNA fragmentation (comet tail) and ROS generation caused by BNMPH and its copper complex. Comet tail assay: (A) control; (B) $20 \mu \mathrm{M}$ BNMPH; (C) $40 \mu \mathrm{M}$ BNMPH; (D) $1.5 \mu \mathrm{M}$ BNMPH-Cu; (E) $3 \mu \mathrm{M}$ BNMPH-Cu.

support the effect of ROS on genetic DNA, the comet assay was conducted. As shown in Fig. 4, the comet tails were clearly observed following exposure to BNMPH (Fig. 4B and C) or its copper complex (Fig. 4D and E), indicating that both agents caused cellular DNA fragmentation. However, it was obvious that the copper complex caused DNA fragmentation more rapidly as it required a much lower concentration compared to BNMPH, which was consistent with the result from the ROS generation in vivo (Fig. 2B).

BNMPH and its copper complex induce cell cycle arrest at the $S$ phase. It has been reported that ROS induce cell cycle delay and arrest cell cycle progression at the G1/S boundary (20). We, therefore, evaluated the effect of BNMPH and its copper complex on the cell cycle distribution using PI staining and flow cytometry. As shown in Fig. 5, BNMPH caused an accumulation of cells in the $S$ phase. The percentage of cells in the S phase was significantly increased from $25.60 \%$ to 69.50 and $35.45 \%$ after treatment with 20 and $40 \mu \mathrm{M}$ BNMPH, respectively (Fig. 5B and C). Similarly, the percentage of cells in the
$\mathrm{S}$ phase was significantly increased from $25.60 \%$ to 33.96 and $43.94 \%$ after treatment with 1.5 and $3 \mu \mathrm{M}$ of the BNMPH-Cu complex (Fig. 5D and E), indicating that BNMPH and its copper complex exerted a similar effect on the cell cycle.

Change in lysosomal (autophagosome) membrane permeability (LMP) in cells following exposure to BNMPH and its copper complex. It has been demonstrated that caspase 8 plays a significant role in the engagement of the lysosomal death pathway and Bax is translocated from the cytosol to the lysosomal membrane, indicating that these proteins regulate lysosomal membrane integrity (21). Treatment with BNMPH and its copper complex resulting in upregulation of caspase 8 and Bax (Fig. 3B) may also affect LMP and autophagosome membrane permeability. To test this hypothesis, LysoTracker Red, that accumulates within lysosomes, was used to assess the LMP (22). As shown in Fig. 6A-C, the red fluorescence intensities of the HepG2 cells were significantly increased after exposure to BNMPH and its copper complex, indicating that the LMP was altered. Using a similar procedure, the 


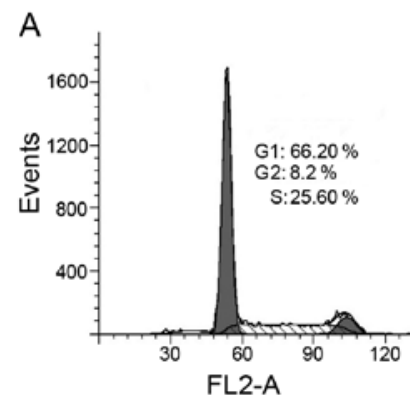

D

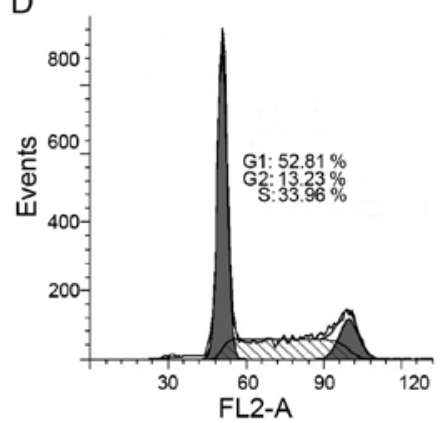

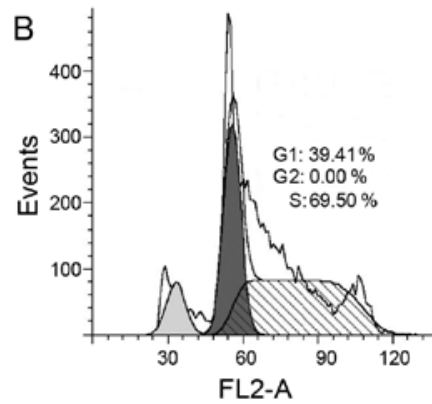

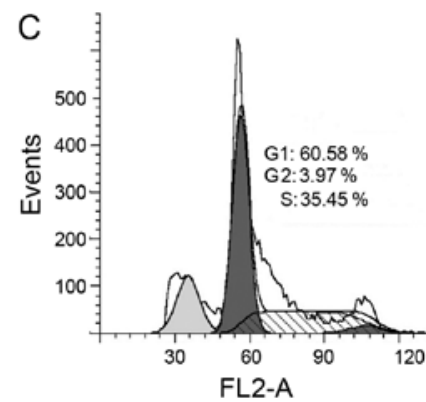

E

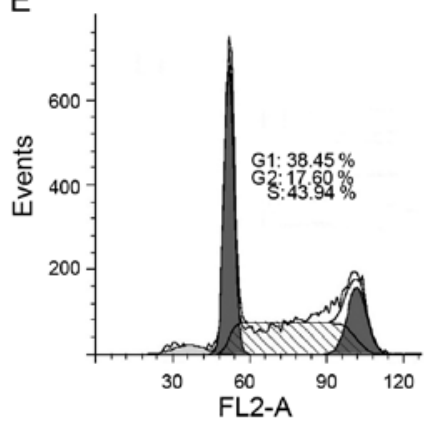

Figure 5. Cell cycle distribution of HepG2 cells following treatment with various concentrations of BNMPH and its Cu complex. (A) Control, (B) $20 \mu \mathrm{M}$ BNMPH, (C) $40 \mu \mathrm{M}$ BNMPH, (D) $1.5 \mu \mathrm{M}$ BNMPH-Cu, (E) $3 \mu \mathrm{M}$ BNMPH-Cu.
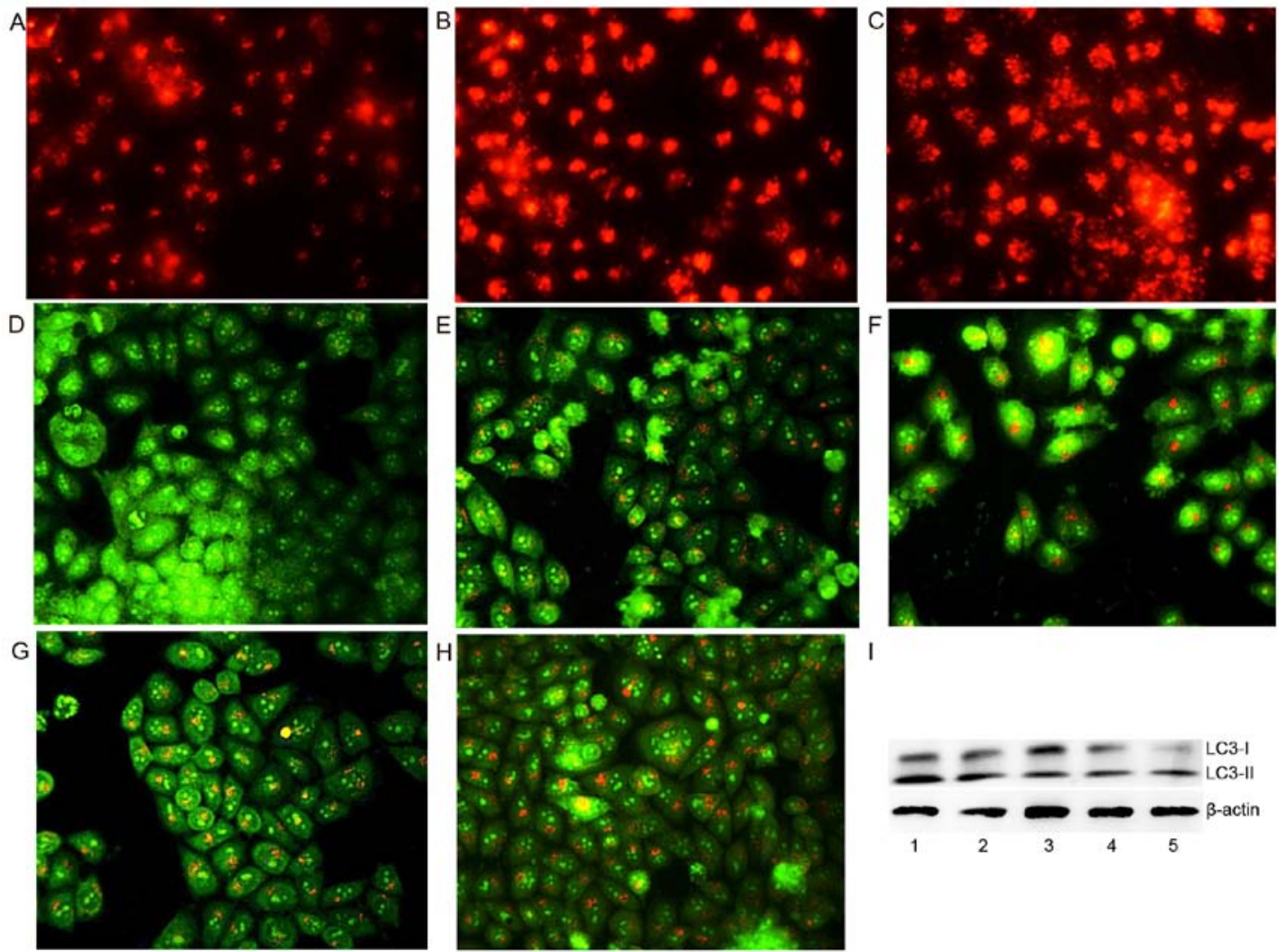

।

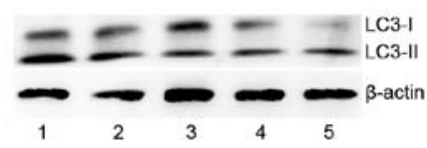

Figure 6. BNMPH and its copper complex induce autophagy (or changes in LMP) in HepG2 cells. (A) LysoTracker Red stained HepG2 cells (control), (B) $20 \mu \mathrm{M}$ BNMPH, (C) $1.5 \mu \mathrm{M}$ BNMPH-Cu, (D) control, (E) $20 \mu \mathrm{M}$ BNMPH, (F) $40 \mu \mathrm{M}$ BNMPH, (G) $1.5 \mu \mathrm{M} \mathrm{BNMPH-Cu}$, (H) $3 \mu \mathrm{M} \mathrm{BNMPH-Cu}$. (I) Immunoblotting of molecular markers of autophagy in the presence or absence of the investigated agents: lane 1, $20 \mu \mathrm{M} \mathrm{BNMPH}$; lane $2,40 \mu \mathrm{M} \mathrm{BNMPH}$; lane 3, control; lane 4, $1.5 \mu \mathrm{M}$ BNMPH-Cu; lane 5, $3 \mu \mathrm{M} \mathrm{BNMPH-Cu}$ for $24 \mathrm{~h}$.

autophagosomes were stained by acridine orange (Fig. 6D-H). As expected, the red fluorescence in acidic vacuoles was observed in the HepG2 cells following treatment with the agents when compared to the control (Fig. 6D), suggesting that 
the agents may induce autophagy. To further determine the involvement of autophagy, the microtuble-associated protein light chain 3 (LC3), an autophagosome marker, was detected by western blotting. An increase in cleaved LC3-II and a decrease in LC3-I indicated that autophagy occurred after exposure of the cells to the agents (Fig. 6I). In view of the involvement of apoptosis, autophagy may be an apoptosis-associated phenomenen. The results demonstrated that BNMPH and its copper complex had a similar action of mechanism. A difference was noted only in the concentration applied; the copper complex appeared to have a stronger effect than BNMPH in regards to the destruction of LMP.

\section{Discussion}

Alkylating agents are a class of antineoplastic drugs. They substitute alkyl groups for hydrogen atoms on DNA, resulting in the formation of crosslinks within the DNA chain thereby resulting in cytotoxic, mutagenic and carcinogenic effects. Caspase-dependent apoptosis, ROS generation and mitochondrial damage are frequently observed concurrently in cells exposed to anticancer drug treatment (20). Copper complexes exhibiting enhanced cytotoxicity when compared to the ligand alone in cancer cells have been observed in numerous studies $(23,24)$. The potent mechanisms proposed to interpret their biological activities include via the lysosome (25), proteasome (17) or inducing oxidative stress $(22,26)$. We introduced a chelation group into an alkylating agent, which may chelate iron (or the copper ion) from a labile iron (copper) pool, and the iron (copper) chelate may be redox active and participate in the Fenton-like reaction to generate ROS, thus improving the cytotoxic effect of the drugs. As expected, BNMPH exhibited significant antitumor activity, and notably the formation of the copper complex markedly enhanced its antitumor activity compared to the ligand (Fig. 1B and C) as shown in previous research (12). However, the underlying mechanism has received limited attention. As an extended study, we evaluated the effect of BNMPH on the Fenton reaction, a well documented ROS generation system. We found that both BNMPH-Fe and BNMPH-Cu complexes were redox active, promoting ROS production in vitro. To support this finding, we determined whether or not the cytotoxicity of these agents was related to ROS. An assay in vivo was conducted and showed that the copper complex was more efficient than BNMPH in ROS generation (Fig. 2A and B), which may be correlated with the enhanced cytotoxicity. Thus, we speculated that the proliferation inhibitory effect of both BNMPH and its copper complex is closely related to their capacity for ROS induction except that DNA alkylation and the cytotoxicity of the BNMPH-Cu complex involved redox cycling, while the weaker activity of BNMPH may reflect its weaker binding ability of capturing iron from the labile iron pool. It has been demonstrated that ROS induce many biological effects including lipid oxidation and DNA fragmentation, which contribute to cytotoxicity (27). To find the correlation between ROS and DNA cleavage, a comet assay was also conducted. The results indicated that BNMPH-induced cellular DNA breakage required a higher dose, while its copper complex required a much lower dose (Fig. 4A-E), which was consistent with the ROS assay in vivo and correlated positively with their cytotoxicity.
Apoptosis (programmed cell death) is a cascade of events leading to the upregulation of caspases through intrinsic and extrinsic pathways. Induction of apoptosis by ROS has been previously demonstrated $(28,29)$. In the present study, both BNMPH and its copper complex induced massive ROS formation which indicated the antitumor activity of the agents may be via the apoptosis pathway. Therefore, the expression levels of apoptosis-related genes were evaluated. As expected, expression levels of caspase 8 and Bax were upregulated, while the expression level of Bcl-2 was downregulated in a dosedependent manner (Fig. 3A and B), as demonstrated previously in many studies $(26,29)$, supporting that ROS mediate caspase activation and apoptosis (30). The cell cycle checkpoint is an important target for various drugs, and ROS-induced cell cycle arrest has been previously demonstrated $(31,32)$, BNMPH and its copper complex may have similar action. Flow cytometry was used to investigate their effect on the cell cycle of HepG2 cells. Both agents induced cell cycle arrest in the $\mathrm{S}$ phase (Fig. 5A-E), indicating they exhibited a similar action on the cell cycle. To understand the above phenomenon, the gene expression of cyclin D1, an S phase cell cycle gate keeper protein was evaluated, and downregulation of cyclin D1 was observed (Fig. 3B). It has been demonstrated that cyclin D1 must be suppressed in favor of entry to the $S$ phase for it has the capacity to inhibit DNA synthesis by virtue of its ability to bind the critical regulator of DNA synthesis, PCNA (33). Both BNMPH and its copper complex downregulated cyclin D1 expression in a dose-dependent manner, indicating that they share a similar mechanism by which to disturb cell progression. Although the decrease of cyclin D1 favored entry of the cell to the $\mathrm{S}$ phase, the delay during the DNA synthesis may have another reason. It is well known that DNA alkylating agents, in principle, can alkylate DNA via interstrand or intrastrand crosslinking, leading to DNA lesions. BNMPH (or its copper complex) tethers an aromatic mustard that alkylates cellular DNA. The ICL can lead to a stalled replication fork in the $S$ phase (34), and likely activate the cell cycle checkpoint and then arrest cells at the late $S$ to G2 (35) to repair the DNA damage $(36,37)$. Masta et al demonstrated that nitrogen mustard can inhibit transcription and translation in a cell-free system (38). The inhibition by BNMPH and its copper complex as determine by PCR in our study was also observed, indicating that they may inhibit DNA polymerase (data not shown). Those factors could affect the cell process and induce $S$ phase arrest.

Autophagy is an evolutionarily conserved catabolic process (also called type II programmed cell death), that functions in degrading damaged proteins and/or organelles and recycling the materials to maintain the quality of cellular components (39). One characteristic of autophagy is the formation of acidic vesicular organelles (AVOs) (40). ROS-triggered autophagy has been widely investigated (41). We speculated that the proliferation inhibition of BNMPH or its copper complex may involve autophagy. This was preliminarily confirmed by evaluation of the AVOs in HepG2 cells after treatment with the agents using acridine orange staining. Granular red fluorescence in AVOs was formed in autophagosomes (Fig. 6D-H). Further supportive evidence that autophagy was induced was carried out by the immunofluorescence detection of LC3, a marker of autophagy. A decrease in LC3-I and an increase in LC3-II were clearly observed (Fig. 6I). Once autophago- 
somes are formed, subsequently, they fuse with lysosomes to form autolysosomes in which the incorporated organelles are degraded (42). The lysosome formation after exposure of the agents determined by LysoTracker Red (Fig. 6A-C) was correlated with autophagosome formation and both had a similar trend, supporting the notion that the agents induced autophagy. However, whether or not the induced autophagy was due to the cytotoxicity of the agents or a host cellular response needs to be determined, which may require subsequent study.

In conclusion, BNMPH and its copper complex suppressed the growth of HepG2 and HCT-116 cell lines. The possible molecular mechanisms involved were caspase-dependent apoptosis, cell cycle arrest and autophagy, which are related to their ability to generate ROS. The excellent antitumor activity of BNMPH-Cu stemmed from its ability for redox-cycling to generate massive ROS. The introduction of copper into BNMPH (chelation) did not change the mechanism of action.

\section{Acknowledgements}

The present study was supported by grants awarded by the Natural Science Foundation of China (no. 21571153), the Henan Science and Technology Agency (nos. 114300510012 and 152300410118), Xinxiang Medical University (nos. 505026 and YJSCX20447Y), and the Plan of Health Scientific and Technological Innovation Talents of Henan Province (no. 2109901) to S.L..

\section{References}

1. Chen Y and Hu L: Design of anticancer prodrugs for reductive activation. Med Res Rev 29: 29-64, 2009.

2. Marzano C, Pellei M, Tisato F and Santini C: Copper complexes as anticancer agents. Anticancer Agents Med Chem 9: 185-211, 2009.

3. Kratz F: Albumin as a drug carrier: Design of prodrugs, drug conjugates and nanoparticles. J Control Release 132: 171-183, 2008.

4. Firer MA and Gellerman G: Targeted drug delivery for cancer therapy: The other side of antibodies. J Hematol Oncol 5: 70, 2012.

5. Finlay GJ, Wilson WR and Baguley BC: Chemoprotection by 9-aminoacridine derivatives against the cytotoxicity of topoisomerase II-directed drugs. Eur J Cancer Clin Oncol 25: 1695-1701, 1989.

6. Marvania B, Lee PC, Chaniyara R, Dong H, Suman S, Kakadiya R, Chou TC, Lee TC, Shah A and Su TL: Design, synthesis and antitumor evaluation of phenyl $\mathrm{N}$-mustard-quinazoline conjugates. Bioorg Med Chem 19: 1987-1998, 2011.

7. Abraham SA, Edwards K, Karlsson G, MacIntosh S, Mayer LD, McKenzie C and Bally MB: Formation of transition metaldoxorubicin complexes inside liposomes. Biochim Biophys Acta Biomembr 1565: 41-54, 2002.

8. Cuin A, Massabni AC, Pereira GA, Leite CQ, Pavan FR, SestiCosta R, Heinrich TA and Costa-Neto CM: 6-Mercaptopurine complexes with silver and gold ions: Anti-tuberculosis and anticancer activities. Biomed Pharmacother 65: 334-338, 2011.

9. Navarro M, Castro W, González S, Abad MJ and Taylor P: Synthesis and anticancer activity of gold(I)-chloroquine complexes. J Mex Chem Soc 57: 220-229, 2013.

10. Martínez A, Suárez J, Shand T, Magliozzo RS and SánchezDelgado RA: Interactions of arene-Ru(II)-chloroquine complexes of known antimalarial and antitumor activity with human serum albumin (HSA) and transferrin. J Inorg Biochem 105: 39-45, 2011.

11. Li W, Jiang GB, Yao JH, Wang XZ, Wang J, Han BJ, Xie YY, Lin GJ, Huang HL and Liu YJ: Ruthenium(II) complexes: DNA-binding, cytotoxicity, apoptosis, cellular localization, cell cycle arrest, reactive oxygen species, mitochondrial membrane potential and western blot analysis. J Photochem Photobiol B 140: 94-104, 2014.
12. Li CZ, Wang LF, Meng XQ and Zhao H: Synthesis, characterization and antitumor activity of benzaldehyde nitrogen mustard picolinoyl hydrazone complexes. Transit Metab Chem 24: 206-209, 1999.

13. Fu Y, Zhou SF, Liu YX, Yang YL, Sun XZ and Li CZ: The cytotoxicity of benzaldehyde nitrogen mustard-2-pyridine carboxylic acid hydrazone being, involved in topoisomerase II $\alpha$ inhibition. Biomed Res Int 2004: 527042: 2014.

14. Tan M, Zhu J, Pan Y, Chen Z, Liang H, Liu H and Wang H: Synthesis, cytotoxic activity, and DNA binding properties of copper (II) complexes with hesperetin, naringenin, and apigenin Bioinorg Chem Appl 347872: 347872, 2009.

15. Xu DF, Shen ZH, Shi Y, He Q and Xia QC: Synthesis, characterization, crystal structure, and biological activity of the copper complex. Russ J Coord Chem 36: 458-462, 2010.

16. Ruan BF, Liang YK, Liu WD, Wu JY and Tian YP: Synthesis, characterization, and antitumor activities of two copper(II) complexes with pyrazole derivatives. J Coord Chem 65: 2127-2134, 2012.

17. Hindo SS, Frezza M, Tomco D, Heeg MJ, Hryhorczuk L, McGarvey BR, Dou QP and Verani CN: Metals in anticancer therapy: Copper(II) complexes as inhibitors of the $20 \mathrm{~S}$ proteasome. Eur J Med Chem 44: 4353-4361, 2009.

18. Jakubowski W and Bartosz G: 2,7-Dichlorofluorescin oxidation and reactive oxygen species: What does it measure? Cell Biol Int 24: 757-760, 2000.

19. Singh NP, McCoy MT, Tice RR and Schneider EL: A simple technique for quantitation of low levels of DNA damage in individual cells. Exp Cell Res 175: 184-191, 1988.

20. Brodská B and Holoubek A: Generation of reactive oxygen species during apoptosis induced by DNA-damaging agents and/ or histone deacetylase inhibitors. Oxid Med Cell Longev 2011: 253529, 2011.

21. Johansson AC, Appelqvist H, Nilsson C, Kågedal K, Roberg K and Ollinger K: Regulation of apoptosis-associated lysosomal membrane permeabilization. Apoptosis 15: 527-540, 2010.

22. Rehman SU, Zubair H, Sarwar T, Husain MA, Ishqi HM, Nehar S and Tabish M: Redox cycling of Cu(II) by 6-mercaptopurine leads to ROS generation and DNA breakage: Possible mechanism of anticancer activity. Tumour Biol 36: 1237-1244, 2015.

23. Yang Y, Huang T, Zhou S, Fu Y, Liu Y, Yuan Y, Zhang Q, Li S and Li C: Antitumor activity of a 2-pyridinecarboxaldehyde 2-pyridinecarboxylic acid hydrazone copper complex and the related mechanism. Oncol Rep 34: 1311-1318, 2015.

24. Fu Y, Yang Y, Zhou S, Liu Y, Yuan Y, Li S, Li C and Li CZ: Ciprofloxacin containing Mannich base and its copper complex induce antitumor activity via different mechanism of action. Int $J$ Oncol 45: 2092-2100, 2014.

25. Lovejoy DB, Jansson PJ, Brunk UT, Wong J, Ponka P and Richardson DR: Antitumor activity of metal-chelating compound $\mathrm{Dp} 44 \mathrm{mT}$ is mediated by formation of a redox-active copper complex that accumulates in lysosomes. Cancer Res 71: 5871-5880, 2011.

26. Fatfat M, Merhi RA, Rahal O, Stoyanovsky DA, Zaki A, Haidar H, Kagan VE, Gali-Muhtasib H and Machaca K: Copper chelation selectively kills colon cancer cells through redox cycling and generation of reactive oxygen species. BMC Cancer 14: 527, 2014.

27. Fussell KC, Udasin RG, Gray JP, Mishin V, Smith PJ, Heck DE and Laskin JD: Redox cycling and increased oxygen utilization contribute to diquat-induced oxidative stress and cytotoxicity in Chinese hamster ovary cells overexpressing NADPH-cytochrome P450 reductase. Free Radic Biol Med 50: 874-882, 2011.

28. Elmore S: Apoptosis: A review of programmed cell death. Toxicol Pathol 35: 495-516, 2007.

29. Guerriero JL, Ditsworth D, Catanzaro JM, Sabino G, Furie MB, Kew RR, Crawford HC and Zong WX: DNA alkylating therapy induces tumor regression through an HMGB1-mediated activation of innate immunity. J Immunol 186: 3517-3526, 2011.

30. Moungjaroen J, Nimmannit U, Callery PS, Wang L, Azad N, Lipipun V, Chanvorachote P and Rojanasakul Y: Reactive oxygen species mediate caspase activation and apoptosis induced by lipoic acid in human lung epithelial cancer cells through Bcl-2 down-regulation. J Pharmacol Exp Ther 319: 1062-1069, 2006.

31. Chatterjee S, Kundu S, Sengupta S and Bhattacharyya A: Divergence to apoptosis from ROS induced cell cycle arrest: Effect of cadmium. Mutat Res 663: 22-31, 2009. 
32. Kumar R, Dwivedi PD, Dhawan A, Das M and Ansari KM: Citrinin-generated reactive oxygen species cause cell cycle arrest leading to apoptosis via the intrinsic mitochondrial pathway in mouse skin. Toxicol Sci 122: 557-566, 2011.

33. Xiong Y, Zhang H and Beach D: D type cyclins associate with multiple protein kinases and the DNA replication and repair factor PCNA. Cell 71: 505-514, 1992.

34. Dronkert ML and Kanaar R: Repair of DNA interstrand crosslinks. Mutat Res 486: 217-247, 2001.

35. Ben-Yehoyada M, Wang LC, Kozekov ID, Rizzo CJ, Gottesman ME and Gautier J: Checkpoint signaling from a single DNA interstrand crosslink. Mol Cell 35: 704-715, 2009.

36. Zhou BB and Elledge SJ: The DNA damage response: Putting checkpoints in perspective. Nature 408: 433-439, 2000.

37. Osawa T, Davies D and Hartley JA: Mechanism of cell death resulting from DNA interstrand cross-linking in mammalian cells. Cell Death Dis 2: e187, 2011.
38. Masta A, Gray PJ and Phillips DR: Nitrogen mustard inhibits transcription and translation in a cell free system. Nucleic Acids Res 23: 3508-3515, 1995.

39. Chen Y, Azad MB and Gibson SB: Methods for detecting autophagy and determining autophagy-induced cell death. Can J Physiol Pharmacol 88: 285-295, 2010.

40. Paglin S, Hollister T, Delohery T, Hackett N, McMahill M, Sphicas E, Domingo D and Yahalom J: A novel response of cancer cells to radiation involves autophagy and formation of acidic vesicles. Cancer Res 61: 439-444, 2001.

41. Li L, Ishdorj G and Gibson SB: Reactive oxygen species regulation of autophagy in cancer: Implications for cancer treatment. Free Radic Biol Med 53: 1399-1410, 2012.

42. Kanematsu S, Uehara N, Miki H, Yoshizawa K, Kawanaka A, Yuri $\mathrm{T}$ and Tsubura A: Autophagy inhibition enhances sulforaphane-induced apoptosis in human breast cancer cells. Anticancer Res 30: 3381-3390, 2010. 